\title{
CORRECTION
}

\section{Correction: The effect of methylphenidate on social cognition and oxytocin in children with attention deficit hyperactivity disorder}

Orit Levi-Shachar ${ }^{1,2}$, Hila Z. Gvirts $\mathbb{D}^{3}$, Yiftach Goldwin ${ }^{2}$, Yuval Bloch ${ }^{1,2}$, Simone Shamay-Tsoory ${ }^{4}$, Orna Zagoory-Sharon ${ }^{5}$, Ruth Feldman ${ }^{5}$ and Hagai Maoz ${ }^{1,2}$

Neuropsychopharmacology (2020) 45:438; https://doi.org/10.1038/s41386-019-0533-2

Correction to: Neuropsychopharmacology https://doi.org/10.1038/ s41386-019-0522-5, published online 12 September 2019
The original version of this Article contained an error in the spelling of the author Orit Levi-Shachar, which was incorrectly given as Orit Levi-Sachar. This has now been corrected in both the PDF and HTML versions of the Article.

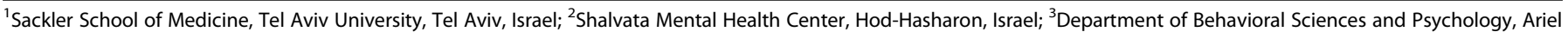
University, Ariel, Israel; ${ }^{4}$ Department of Psychology, Haifa University, Haifa, Israel and ${ }^{5}$ Baruch Ivcher School of Psychology, Interdisciplinary Center, Herzlia, Israel Correspondence: Hagai Maoz (hagaima@gmail.com)

Published online: 9 October 2019 